TITLE:

\title{
Fiber-content dependency of the optical transparency and thermal expansion of bacterial nanofiber reinforced composites
}

\section{AUTHOR(S):}

Nogi, Masaya; Ifuku, Shinsuke; Abe, Kentaro;

Handa, Keishin; Nakagaito, Antonio Norio; Yano, Hiroyuki

\section{CITATION:}

Nogi, Masaya ... [et al]. Fiber-content dependency of the optical transparency and thermal expansion of bacterial nanofiber reinforced composites. Applied Physics Letters 2006, 88(13): 133124.

\section{ISSUE DATE:}

2006-03

URL:

http://hdl.handle.net/2433/84903

\section{RIGHT:}

c 2006 American Institute of Physics. 


\title{
Fiber-content dependency of the optical transparency and thermal expansion of bacterial nanofiber reinforced composites
}

\author{
Masaya Nogi, ${ }^{\text {a) }}$ Shinsuke Ifuku, and Kentaro Abe \\ International Innovation Center, Kyoto University, Nishikyo-ku, Kyoto 606-8501, Japan \\ Keishin Handa \\ Mitsubishi Chemical Group Science and Technology Research Center, Mitsubishi Chemical Corporation, \\ Yokohama, Kanagawa 227-8502, Japan
}

\author{
Antonio Norio Nakagaito and Hiroyuki Yano \\ Research Institute for Sustainable Humanosphere, Kyoto University, Uji, Kyoto 611-0011, Japan
}

(Received 30 October 2005; accepted 7 March 2006; published online 31 March 2006)

\begin{abstract}
We produced transparent nanocomposite reinforced with bacterial cellulose having a wide range of fiber contents, from 7.4 to $66.1 \mathrm{wt} \%$, by the combination of heat drying and organic solvent exchange methods. The addition of only $7.4 \mathrm{wt} \%$ of bacterial cellulose nanofibers, which deteriorated light transmittance by only $2.4 \%$, was able to reduce the coefficient of thermal expansion of acrylic resin from $86 \times 10^{-6}$ to $38 \times 10^{-6} \mathrm{~K}^{-1}$. As such, the nanofiber network of bacterial cellulose has an extraordinary potential as a reinforcement to obtain optically transparent and low thermal expansion materials. (c) 2006 American Institute of Physics.
\end{abstract}

[DOI: $10.1063 / 1.2191667]$

Bacterial cellulose (BC), cellulosic nanofibers produced by bacteria, has extraordinary potential as a reinforcement to obtain optically transparent materials. Since bacterial cellulose nanofiber is a ribbon-shaped fiber of $10 \times 50 \mathrm{~nm},{ }^{1-4}$ it can be used to reinforce transparent plastics with less than $10 \%$ loss of light transmittance, even at fiber contents as high as $70 \mathrm{wt} \%{ }^{5}$ Because the nanofibers are made up of bundles of semicrystalline extended cellulose chains, their Young's modulus and tensile strength are $138 \mathrm{GPa}$ (Ref. 6) and at least $2 \mathrm{GPa}^{7}$ respectively, and surprisingly, the thermal expansion in the axial direction is less than $0.1 \times 10^{-6} \mathrm{~K}^{-1}$. Hence, this nanofiber reinforced composite showed incredibly low thermal expansion $\left(3 \times 10^{-6} \mathrm{~K}^{-1}\right)$ and high tensile strength $(325 \mathrm{MPa})$, while maintaining the flexibility and ductility of many plastics. ${ }^{5}$ Besides, due to the nanofiber size effect, high transparency was obtained against a wide distribution of resin refractive indexes, from 1.492 to 1.636 at $20{ }^{\circ} \mathrm{C} .{ }^{9}$ The optical transparency was also insensitive to temperature increases up to $80^{\circ} \mathrm{C} .{ }^{9}$ These nanofiber-networkreinforced polymer composites should lead the way to a wider use of optically transparent polymers in optoelectronic devices such as substrates for flexible displays and components for precision optical devices, which demand high transparency and low thermal expansion.

However, to further enhance the transparency of $\mathrm{BC}$ nanocomposites, maintaining their low thermal expansion and high strength, their optimum fiber-content must be elucidated based on the fiber-content dependency of the properties. Hence, in this Letter, we developed a method to produce $\mathrm{BC}$ composites in a wider fiber-content range and clarified the changes of regular light transmittance and the coefficient of thermal expansion (CTE) of the composites against fiber content.

$\mathrm{BC}$ pellicles with a thickness of $10 \mathrm{~mm}$ consisting of $1 \mathrm{vol} \% \mathrm{BC}$ nanofibers and $99 \mathrm{vol} \%$ water were used as the

\footnotetext{
${ }^{a)}$ Electronic mail: nogi@rish.kyoto-u.ac.jp
}

starting material. ${ }^{5,9}$ When the pellicles were pressed to onetenth of their original thickness to squeeze out the water and then dried, the $\mathrm{BC}$ sheets shrank during the drying and their density became $1.0-1.2 \mathrm{~g} / \mathrm{cm}^{3}$. As the density of the cellulose microfibrils is $1.6 \mathrm{~g} / \mathrm{cm}^{3}$, the interstitial cavities in the dried sheets were estimated to account for $1 / 3-1 / 4$ of the volume. Thus, when these cavities were completely filled by impregnating the sheets with neat acrylic resin [tricyclodecane dimethanol dimethacrylate (TCDDMA)] under a reduced pressure and cured by UV light, ${ }^{5,9}$ the fiber content of the $\mathrm{BC}$ nanocomposites was restricted to a range of $52.4-66.1 \mathrm{wt} \%$.

To produce $\mathrm{BC}$ nanocomposites with lower fiber contents, it is necessary to prevent cohesion of $\mathrm{BC}$ nanofibers during the evaporation of water. Thus, organic solvents that are soluble in both water and acrylic resin were applied for the removal of water from $\mathrm{BC}$ pellicles instead of drying. That is, the $\mathrm{BC}$ pellicles were compressed, adjusting the thickness by a cold press to control the fiber content, and were dipped into a mixture of water and acetone, the concentration of which was increased from $50 \%$ to $100 \%$ step by step, to prevent nanofiber cohesion. Afterwards, the solvent-replaced sheets were impregnated with neat acrylic resin under reduced pressure and UV cured. The acetone was completely evaporated during the resin impregnation under reduced pressure. This method enabled the production of nanocomposites with lower fiber contents in a range of $19.0-49.0 \mathrm{wt} \%$. The fiber contents of BC nanocomposites were determined by elemental analysis.

When ethanol was used as a solvent, due to its higher polarity, the thickness adjusted $\mathrm{BC}$ sheets swelled during the impregnation of acrylic resin. As a result, BC nanocomposites with fiber content in the range of $7.4-35.2 \mathrm{wt} \%$ were obtained. Consequently, the study of the fiber-content dependency of the optical transparency and thermal expansion of bacterial nanofiber reinforced composites became possible in a wider fiber-content range, from 7.4 to $66.1 \mathrm{wt} \%$. The re- 

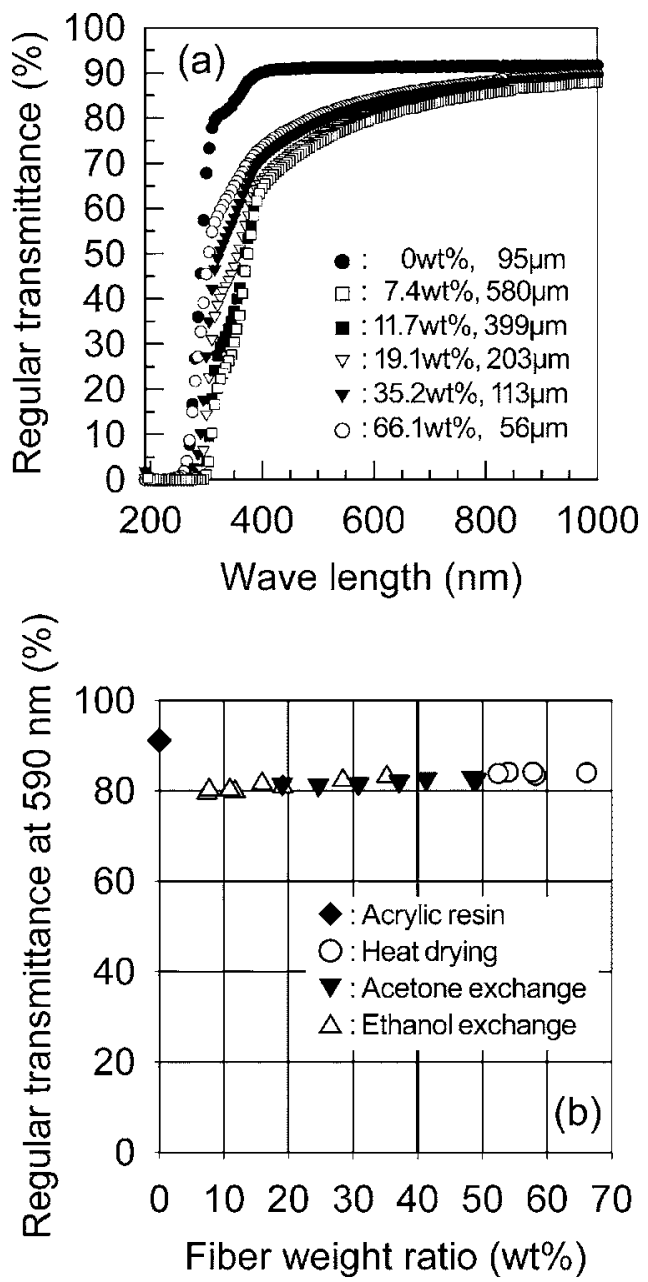

FIG. 1. Regular transmittance spectra (a) and the regular transmittance at $590 \mathrm{~nm}$ (b) of BC nanocomposite of various fiber contents (wt \%) and thicknesses $(\mu \mathrm{m})$.

sulting thickness of the composites was distributed from 56 to $580 \mu \mathrm{m}$.

Regular luminous transmittances were measured at wavelengths from 190 to $1000 \mathrm{~nm}$ using a UV-visible spectrometer with an integrating sphere $60 \mathrm{~mm}$ in diameter (U-4100, Hitachi High-Tech. Corp.). Regular transmittance was measured by placing the specimens $25 \mathrm{~cm}$ from the entrance port of the integrating sphere. The regular transmittances of $\mathrm{BC}$ nanocomposite sheets against various fiber contents are shown in Fig. 1. In Fig. 1(a), the regular transmittance spectra of acrylic resin and the $\mathrm{BC}$ nanocomposite produced by heat drying or by ethanol exchange are compared. All the composites absorb light below $400 \mathrm{~nm}$ affected by the optical characteristics of the acrylic resin and the transmittance gradually increases with increasing wavelength. Despite the wide distribution of fiber content and sample thickness as described above, all the BC nanocomposites transmitted more than $75 \%$ of the light in the wavelength of 500-800 nm, including Fresnel's reflection. However, careful comparison of the transmittance spectra against various fiber contents revealed an unexpected dependency; that is, the transmittance decreased in spite of the decrease in fiber content.

To investigate the dependency more precisely, the regular transmittances of $\mathrm{BC}$ nanocomposite at $590 \mathrm{~nm}$ were compared, as shown in Fig. 1(b). It was discovered that deDownloaded 24 Aug 2009 to 130.54 .110 .32 . Redistribution subject

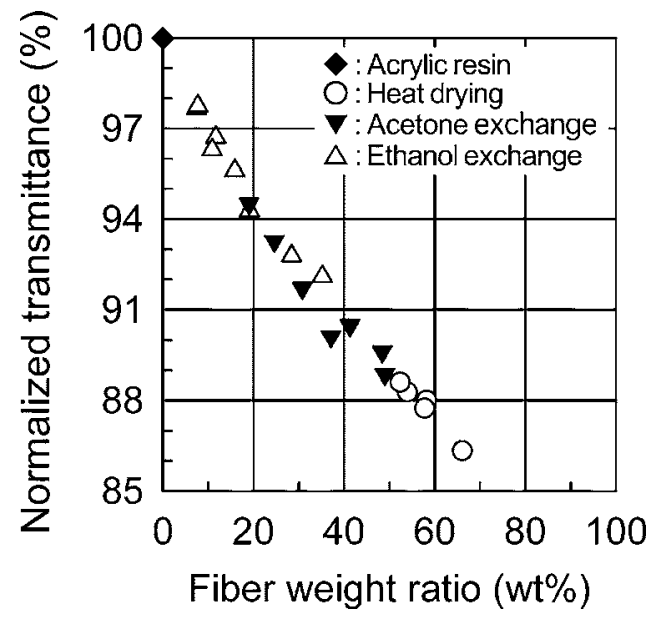

FIG. 2. Normalized regular transmittance at $590 \mathrm{~nm}$ and $100 \mu \mathrm{m}$ thickness of $\mathrm{BC}$ nanocomposite against fiber content.

creasing the fiber content from 66.1 to $7.4 \mathrm{wt} \%$ leads to a reduction of the regular transmittance from $84.1 \%$ to $79.5 \%$.

In the production of $\mathrm{BC}$ composites, fiber contents were adjusted by changing the thickness of the composite while maintaining the same amount of bacterial cellulose. The transmittances are influenced not only by their fiber contents but also by their thicknesses. Thus, to discuss the fibercontent dependency of the optical transparency excluding the effect of sample thickness, the regular transmittances at $590 \mathrm{~nm}$ of BC nanocomposites with $100 \mu \mathrm{m}$ thickness were calculated by defining the regular transmittance of acrylic resin as $100 \% .^{10}$ As shown in Fig. 2, it was found that the normalized transmittance of $\mathrm{BC}$ nanocomposites increased against the decrease of fiber content linearly and regardless of the sample preparation methods.

Haraguchi and Usami reported that the light transmittance of a transparent phenolic resin sheet $100 \mu \mathrm{m}$ thick deteriorated by $15 \%$ when $20 \mathrm{~nm}$ silica nanoparticles were well dispersed by $10 \mathrm{wt} \%$ using the sol-gel method. ${ }^{11}$ Contrary to this, with BC nanocomposites, the reduction of the regular transmittance at the fiber content of $11.7 \mathrm{wt} \%$ was only $3.3 \%$ (Fig. 2). Even at fiber contents as high as $66.1 \mathrm{wt} \%$, the loss of transparency was a mere $13.7 \%$ (Fig. 2). This clearly indicates that the bacterial cellulose has an extraordinary potential as a reinforcement to obtain optically transparent materials.

As mentioned above, lower fiber content is preferable from the viewpoint of high light transmittance of $\mathrm{BC}$ composites; however, decreasing fiber content could detract from the low CTE of BC composites. Hence, the CTEs of BC composites were evaluated against the fiber content. The CTEs were measured by a thermomechanical analyzer (TMA/SS6100, SII Nanotechnology Inc.). Specimens were $25 \mathrm{~mm}$ long and $3 \mathrm{~mm}$ wide with a $20 \mathrm{~mm}$ span. After heating at $180^{\circ} \mathrm{C}$ for $2 \mathrm{~h}$ in a nitrogen atmosphere to postcure the acrylic resin, the measurements were carried out three times with a heating rate of $5{ }^{\circ} \mathrm{C} / \mathrm{min}$ in a nitrogen atmosphere in tensile mode under a negligible load of $3 \mathrm{mg}$ to detect the thermal strain. The CTE values were determined as the mean values at $20-150{ }^{\circ} \mathrm{C}$ in the second run.

Surprisingly, the addition of only $7.4 \mathrm{wt} \%$ of BC nanofibers, which deteriorated light transmittance only by $2.4 \%$ (Fig. 2), could reduce the CTE of acrylic resin from $86 \times 10^{-6}$ to $38 \times 10^{-6} \mathrm{~K}^{-1}$ (Fig. 3). This is an excellent reo AlP license or copyright; see http://apl.aip.org/apl/copyright.jsp 


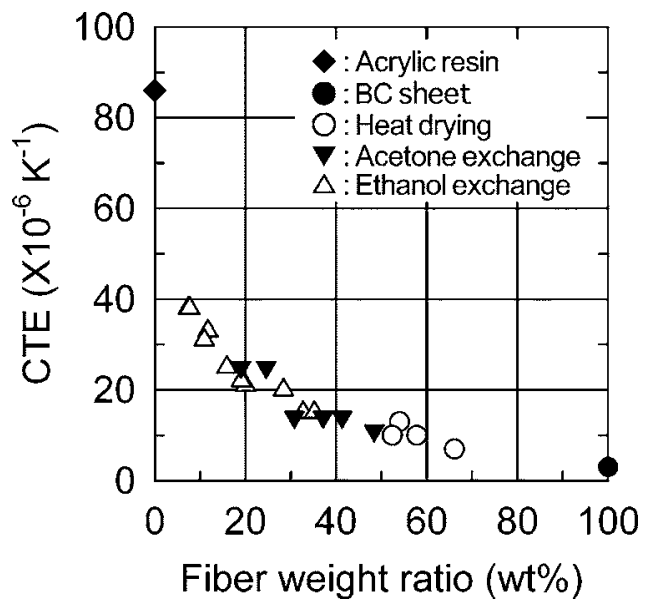

FIG. 3. The coefficients of thermal expansion of $\mathrm{BC}$ nanocomposites with various fiber contents.

inforcement effect if compared to polyimide (59 $\left.\times 10^{-6} \mathrm{~K}^{-1}\right) /$ silica nanohybrids, which resulted in just $20 \%$ reduction of CTE at a filler content of $5 \mathrm{wt} \%$, accompanied by $30 \%$ degradation in transparency. ${ }^{12,13}$ Even when microsized silica particles with extremely low CTE of 0.5 $\times 10^{-6} \mathrm{~K}^{-1}$ were mixed with cyanate ester resin (68 $\times 10^{-6} \mathrm{~K}^{-1}$ ) up to $70 \mathrm{wt} \%$, the reduction of CTE against filler content was linear and resulted in 34\% of the CTE of the matrix. ${ }^{14}$ On the other hand, BC nanocomposites' CTEs drastically decreased to $15 \times 10^{-6} \mathrm{~K}^{-1}$ up at around $30 \mathrm{wt} \%$ fiber content and then gradually declined to $10 \times 10^{-6} \mathrm{~K}^{-1}$ above $50 \mathrm{wt} \%$ fiber content, which is only $12 \%$ of the original acrylic resin (Fig. 3). It should be pointed out that the nanofiber network of BC might play an important role in the drastic reduction of CTE.

In conclusion, we produced bacterial cellulose nanocomposites with a wide range of fiber contents, from 7.4 to $66.1 \mathrm{wt} \%$, by the combination of heat drying and or- ganic solvent exchange methods. The addition of bacterial cellulose nanofibers linearly decreased the regular transmittance of the nanocomposites; however, the deterioration of light transmittance was limited to just $13.7 \%$ at a fiber content of $66.1 \mathrm{wt} \%$. The coefficient of thermal expansion was drastically suppressed by the addition of the nanofibers. The addition of only 7.4 wt \% of BC nanofibers, which deteriorated light transmittance by only $2.4 \%$, could reduce the CTE of acrylic resin from $86 \times 10^{-6}$ to $38 \times 10^{-6} \mathrm{~K}^{-1}$, and a coefficient of thermal expansion of $15 \times 10^{-6} \mathrm{~K}^{-1}$ was attained at 30.8 wt \% fiber content.

The BC pellicles were a kind gift from Dr. Y. Kuwana (Fujicco Co., Ltd.). The authors thank Professor Dr. L. Berglund for helpful discussion. This work was supported by a grant-in-aid from the International Innovation Center, Kyoto University.

${ }^{1}$ C. H. Haigler and M. Benziman, in Cellulose and Other Natural Polymer Systems: Biogenesis, Structure, and Degradation, edited by R. M. Brown, Jr. (Plenum, New York, 1982).

${ }^{2}$ P. Ross, R. Mayer, and M. Benziman, Microbiol. Rev. 55, 35 (1991)

${ }^{3}$ R. M. Brown, J. Macromol. Sci., Pure Appl. Chem. A33, 1345 (1996).

${ }^{4}$ M. Iguchi, S. Yamanaka, and A. Budhiono, J. Mater. Sci. 35, 261 (2000).

${ }^{5}$ H. Yano, J. Sugiyama, A. N. Nakagaito, M. Nogi, T. Matsuura, M. Hikita, and K. Handa, Adv. Mater. (Weinheim, Ger.) 17, 153 (2005).

${ }^{6}$ T. Nishino, K. Takano, and K. Nakamae, J. Polym. Sci., Part B: Polym. Phys. 33, 1647 (1995).

${ }^{7}$ D. H. Page and F. El-Hosseiny, J. Pulp Pap. Sci. 9, 99 (1983).

${ }^{8}$ T. Nishino, I. Matsuda, and K. Hirao, Macromolecules 37, 7683 (2004). ${ }^{9}$ M. Nogi, K. Handa, A. N. Nakagaito, and H. Yano, Appl. Phys. Lett. 87, 243110 (2005).

${ }^{10}$ M. Born and E. Wolf, Principles of Optics, 5th ed. (Pergamon, Oxford, 1975).

${ }^{11}$ K. Haraguchi and Y. Usami, Koubunshi Ronbunshu 55, 715 (1983).

${ }^{12}$ H. Wang, W. Zhong, Q. Du, Y. Yang, H. Okamoto, and S. Inoue, Polym. Bull. (Berlin) 51, 63 (2003).

${ }^{13}$ H. Wang, W. Zhong, P. Xu, and Q. Du, Macromol. Mater. Eng. 289, 793 (2004).

${ }^{14}$ T. J. Wooster, S. Abrol, J. M. Hey, and D. R. MacFarlane, Composites, Part A 35, 75 (2004). 